\title{
Prevalence of psychiatric disorders during pregnancy and their effect on birth weight
}

\author{
Elif Karaahmet ${ }^{1}$, Ayse Nur Cakir Gungor ${ }^{2}$, Naci Topalogluª Basak Sahin ${ }^{1}$, Yuksel Kivrak ${ }^{4}$
}

\author{
${ }^{1}$ Department of Psychiatry, Faculty of Medicine, Canakkale Onsekiz Mart University, \\ Canakkale, Turkey \\ 2Department of Obstetrics and Gynecology, Faculty of Medicine, Canakkale Onsekiz \\ Mart University, Canakkale, Turkey \\ ${ }^{3}$ Department of Pediatrics, Faculty of Medicine, Canakkale Onsekiz Mart University, \\ Canakkale, Turkey \\ ${ }^{4}$ Department of Psychiatry, Faculty of Medicine, Kars Kafkas University, Kars, Turkey
}

Submitted: 23 March 2016

Accepted: 22 April 2016

Arch Med Sci Civil Dis 2016; 1: e24-e29

DOI: 10.5114 /amscd.2016.60040

Copyright (c) 2016 Termedia \& Banach

\section{Abstract}

Introduction: The aim of this study was to assess the prevalence of psychiatric disorders during pregnancy and their effects on obstetric outcomes. Material and methods: All participating pregnant women, in their first visit to our obstetric department, completed an anxiety questionnaire and were evaluated in person by a psychiatrist to determine the presence of psychiatric disorders.

Results: Of 182 patients, 79 (43.4\%) were diagnosed with an axis 1 disorder according to the parameters of the Structured Clinical Interview for DSM-IV (SCID-I). Of those diagnosed, there was a significant correlation between low income and high anxiety questionnaire scores. Low incomes $(p=0.014)$ and unplanned pregnancies $(p=0.001)$ were more prevalent among those with an SCID-1 anxiety diagnosis than among those in the control group. Finally, on average, patients diagnosed with depression delivered babies with significantly lower birth weights than babies born to patients in the control group. Conclusions: Depressive symptoms and anxiety disorders are relatively common in pregnant women and might interfere with pregnancy outcomes. Further studies should investigate whether treating depression in pregnant women improves obstetric outcomes. Decreasing the number of unplanned pregnancies by raising awareness about effective birth control methods and choosing appropriate contraceptive methods could lower the prevalence of anxiety in pregnant women.

Key words: pregnancy, psychiatric disorders, depression, anxiety.

\section{Introduction}

Pregnant women adapt to many physiological, psychological, and social changes that occur during the gestational period. Antenatal mental illnesses are more prevalent in developing countries and in women with low socio-economic or educational statuses [1, 2]. Antenatal mental illness can complicate both pregnancy and the postpartum period and can affect maternal and fetal outcomes [3]. Depressive and anxiety disorders are the most common psychiatric conditions experienced during pregnancy [4]. However, studies on both the prevalence of depression and anxiety and their effect on pregnancy outcomes have conflicting results.

\author{
Corresponding author: \\ Ayse Nur Cakir Gungor \\ Obstetrics and Gynecology \\ Department \\ Medicine Faculty \\ Canakkale Onsekiz \\ Mart University \\ 17100 Canakkale, Turkey \\ Phone: +90 2862635950 \\ Fax: +90 2862180516 \\ E-mail: dr_aysecakir@ \\ hotmail.com
}


The prevalence of depression during pregnancy varies from $5 \%$ to $25 \%$ [5-7], and the prevalence of anxiety disorders during pregnancy varies from $6 \%$ to $21 \%$ [8-10]. Some studies [11, 12] conclude that depression and anxiety disorders complicate perinatal outcomes by leading to preterm birth, low birth weight, and low APGAR scores; others, however, report no significant impact of antenatal depression and anxiety on birth outcomes $[13,14]$.

The aim of this study was to assess the effects of psychiatric disorders on obstetric outcomes.

\section{Material and methods}

\section{Participants}

For this study, 182 pregnant women who attended the obstetric outpatient clinic of Canakkale Onsekiz Mart University Education and Research Hospital were recruited. Recruitment took place between January 1, 2012 and December 31, 2012, during patients' first visit to the obstetric outpatient clinic. To participate in the study, patients had to be pregnant women who spoke and understood Turkish. Exclusion criteria included being illiterate, having a mental deficiency, and refusing to participate in the study.

During the recruitment period, 222 women attended our outpatient clinic; 3 women were illiterate, 14 refused to participate, and 23 women dropped out of the study and were thus excluded. The remaining 182 women were included in the study.

\section{Procedures and instruments}

All participants provided written informed consent, and, in cases of participants 18 years old or younger, written parental consent was obtained. The study was approved by the Medical Ethics Committee of Canakkale Onsekiz Mart University.

The socio-demographic characteristics and results of obstetric evaluations were recorded at the obstetric outpatient clinic. Participants were then referred to psychiatrists and they completed the questionnaire. Next, psychiatrists at the Service of Psychiatry clinics gave psychiatric diagnoses by using the parameters of the Structured Clinical Interview for DSM-IV Axis I Dosorder (SCID-I). Participants were re-evaluated after delivery for obstetric outcomes and neonatal assessments.

All socio-demographic, obstetric, and psychiatric variables were analyzed with State-Trait Anxiety Inventory (STAI) scores to identify possible risk factors for the development of antenatal depression and anxiety disorders. The following risk factors were analyzed: age, smoking and alcohol consumption status, nationality, level of education, employment and income, multiparity, socio-economic stress factors, conflictual relationship with family, conflictual relationship with part- ner, organic pathologies in previous pregnancy and obstetric complications, infertility treatment, unplanned pregnancy, depressive illness, and anxiety before and during pregnancy.

\section{Instruments - demographic questionnaire}

A semi-structured questionnaire was designed to obtain the following variables: socio-demographic data, alcohol consumption and smoking, social support, obstetric outcome.

The STAI was developed by Spielberger et al. [15] to separately determine state and trait anxiety levels. Patients also completed the STAI, a self-administered questionnaire composed of two parts: a state anxiety scale consisting of 20 items that evaluate current feelings of tension and anxiety, and a 20-item trait scale that assesses general anxiety levels. The reliability and validity of the Turkish version of the STAI was confirmed by Öner et al. [16].

\section{Statistical analysis}

Statistical analyses were performed using SPSS software version 19.0. Variables were investigated using visual and analytical methods (Kolmogorov-Smirnov/Shapiro-Wilk test) to determine whether they were normally distributed among patients with and without depression diagnoses. Continuous variables were defined as mean \pm standard deviation (SD), and categorical variables were expressed as a case number and percentage. A $\chi^{2}$ test was used to compare categorical variables in different groups. A $p$-value of less than 0.05 was considered statistically significant.

\section{Results}

The sample group was composed of 182 women with a mean age of $28.19 \pm 5.18$. Every participant was married and 110 (59.8\%) had received secondary or higher education. According to the psychiatric assessments, $31 \%$ of the participants had never been diagnosed with a psychiatric disorder.

The first prenatal checkup performed by an obstetrician occurred in the first trimester of $54.5 \%$ of the women, while $41.4 \%$ received their first checkup later on in their pregnancy. The remaining $4.1 \%$ did not receive regular follow-up care by an obstetrician.

Patients were evaluated for present psychopathology using SCID-I parameters, and 79 (43.4\%) women met the criteria for an axis I disorder. The most frequent axis I disorders were mood disorders (present in 42 women, 23\%) and anxiety disorders (present in 37 women, 20.3\%). Mean STAI scores were $34.96 \pm 11.08$ from the state test and $37.71 \pm 9.24$ from the trait test. 
Participant data were first grouped according to STAI-state (Table I) and STAI-trait (Table II) scores. Low income was the only variable significantly correlated with both STAI-state and STAI-trait scores. Patients were then re-grouped according to SCID-1 diagnosis. Low income and unplanned pregnancy were more prevalent among women in the SCID-1 diagnosis group (Table III).

Thirty-five (19.2\%) participants were diagnosed with major depression. When participant data were re-grouped according SCID-1 diagnosis, it was found that the birth weights of babies born to mothers diagnosed with depression were significantly lower than those who were not (Table IV).
There was also a significant relationship between anxiety disorder diagnoses and the low income and unplanned pregnancy variables (Table V).

\section{Discussion}

A majority of the available studies on this subject involve prenatal depression and anxiety disorders. In this study, we evaluated risk factors for depression and psychiatric disorders in pregnant women and analyzed their effects on obstetric outcomes. Psychiatric disorders, according to SCID-1 diagnoses, were present in $43.4 \%$ of participants; the most prevalent SCID-1 diagnoses were

Table I. Comparison of patients according to STAI-state scores

\begin{tabular}{|lccc|}
\hline Parameter & Scores $\leq \mathbf{4 0}(n=130)$ & Scores $>$ 40 $(n=52)$ & $P$-value \\
\hline Age & 28.11 & 28.40 & 0.729 \\
\hline Education $>8$ years & $82(63.1 \%)$ & $12(52.2 \%)$ & 0.311 \\
\hline Low income* & $16(25.4 \%)$ & $36(69.2 \%)$ & 0.119 \\
\hline Planned pregnancy & $104(80.0 \%)$ & $2.07 \pm 1.10$ & 0.336 \\
\hline Gravida* & $1.88 \pm 1.10$ & $1.63 \pm 0.70$ & 0.242 \\
\hline Parity* & $1.49 \pm 0.65$ & $32(61.5 \%)$ & 0.188 \\
\hline Having at least one alive child* & $66(50.8 \%)$ & $0.41 \pm 0.71$ & 0.289 \\
\hline Abortus* & $0.28 \pm 0.66$ & $0.02 \pm 0.16$ & 0.279 \\
\hline Dilatation and Currettage & $0.10 \pm 0.46$ & $3028.27 \pm 431.02$ & 0.197 \\
\hline Birth weight & $3110.77 \pm 369.89$ & $34(65.4 \%)$ & $27(51.9 \%)$ \\
\hline Expecting girl & $82(63.1 \%)$ & $72(55.4 \%)$ & 0.770 \\
\hline Vaginal birth & & 2879 \\
\hline
\end{tabular}

${ }^{\star}$ There are some missing values.

Table II. Comparison of patients according to STAI-trait scores

\begin{tabular}{|c|c|c|c|}
\hline Parameter & Scores $\leq 40(n=119)$ & Scores $>40(n=63)$ & $P$-value \\
\hline Age & 28.10 & 28.37 & 0.744 \\
\hline Education $>8$ years & $77(64.7 \%)$ & $33(53.2 \%)$ & 0.133 \\
\hline Low income* & $11(21.2 \%)$ & $17(50.0 \%)$ & 0.005 \\
\hline Planned pregnancy & $94(79.0 \%)$ & $46(73.0 \%)$ & 0.363 \\
\hline Gravida* & $1.91 \pm 1.14$ & $1.98 \pm 1.02$ & 0.719 \\
\hline Parity* & $1.52 \pm 0.66$ & $1.56 \pm 0.68$ & 0.687 \\
\hline Having at least one alive child* & $61(51.3 \%)$ & $37(58.7 \%)$ & 0.336 \\
\hline Abortus* & $0.28 \pm 0.70$ & $0.40 \pm 0.61$ & 0.341 \\
\hline$D \& C^{*}$ & $0.11 \pm 0.47$ & $0.02 \pm 0.14$ & 0.197 \\
\hline Birth weight & $3110.84 \pm 355.51$ & $3042.54 \pm 444.89$ & 0.261 \\
\hline Expecting girl & $76(63.9 \%)$ & $40(63.5 \%)$ & 0.960 \\
\hline Vaginal birth & $67(0.56 \%)$ & $32(50.8 \%)$ & 0.789 \\
\hline
\end{tabular}


Table III. Comparison of patients according to SCID-1 diagnosis

\begin{tabular}{|lccc|}
\hline Parameter & Without diagnosis $(n=103)$ & With diagnosis $(n=79)$ & $P$-value \\
\hline Age & 27.89 & 28.58 & 0.375 \\
\hline Education $>$ 8 years & $68(66.0 \%)$ & $42(53.8 \%)$ & 0.097 \\
\hline Low income* & $11(22.0 \%)$ & $17(47.2 \%)$ & 0.014 \\
\hline Planned pregnancy & $89(86.4 \%)$ & $51(64.6 \%)$ & 0.001 \\
\hline Gravida* & $1.82 \pm 0.99$ & $2.08 \pm 1.22$ & 0.161 \\
\hline Parity* $^{*}$ & $1.48 \pm 0.65$ & $1.60 \pm 0.69$ & 0.253 \\
\hline Having at least one alive child* & $51(49.5 \%)$ & $47(59.5 \%)$ & 0.181 \\
\hline Abortus* & $0.29 \pm 0.65$ & $0.37 \pm 0.71$ & 0.481 \\
\hline D\&C* & $0.06 \pm 0.24$ & $0.11 \pm 0.54$ & 0.438 \\
\hline Birth weight & $3120.39 \pm 338.10$ & $3043.92 \pm 445.13$ & 0.189 \\
\hline Expecting girl & $65(63.1 \%)$ & $51(64.6 \%)$ & 0.840 \\
\hline Vaginal birth & $58(53.2 \%)$ & $41(51.9 \%)$ & 0.803 \\
\hline *There are some missing values. & & & \\
\hline
\end{tabular}

*There are some missing values.

Table IV. Comparison of patients who have depression without any SCID-1 diagnosis

\begin{tabular}{|lccc|}
\hline Parameter & Without SCID-1 diagnosis $(n=103)$ & With depression $(n=35)$ & $P$-value \\
\hline Age & $27.89 \pm 4.62$ & $28.80 \pm 5.57$ & 0.343 \\
\hline Education $>$ 8 years & $68(66.0 \%)$ & $19(55.9 \%)$ & 0.287 \\
\hline Low income* & $11(22 \%)$ & $7(38.9 \%)$ & 0.164 \\
\hline Planned pregnancy & $89(86.4 \%)$ & $27(77.1 \%)$ & 0.196 \\
\hline Gravida* & $1.82 \pm 0.99$ & $1.92 \pm 1.12$ & 0.673 \\
\hline Parity* & $1.48 \pm 0.65$ & $1.48 \pm 0.65$ & 0.980 \\
\hline Alive child* & $0.44 \pm 0.63$ & $0.48 \pm 0.65$ & 0.785 \\
\hline Abortus* & $0.29 \pm 0.65$ & $0.36 \pm 0.70$ & 0.623 \\
\hline D\&C* & $0.06 \pm 0.24$ & $0.08 \pm 0.28$ & 0.717 \\
\hline Birth weight & $3120.39 \pm 338.10$ & $2970.86 \pm 386.58$ & 0.031 \\
\hline Expecting girl & $65(63.0 \%)$ & $21(60.0 \%)$ & 0.743 \\
\hline Vaginal birth & $58(56.3 \%)$ & $18(51.4 \%)$ & 0.907 \\
\hline
\end{tabular}

${ }^{\star}$ There are some missing values.

Table V. Comparison of patients who have anxiety disorders without any SCID-1 diagnosis

\begin{tabular}{|lccc|}
\hline Parameter & Without SCID-1 diagnosis $(n=103)$ & With anxiety $(n=37)$ & $P$-value \\
\hline Age & $27.89 \pm 4.62$ & $28.19 \pm 5.91$ & 0.757 \\
\hline Education $>$ 8 years & $68(66.0 \%)$ & $19(51.4 \%)$ & 0.115 \\
\hline Low income* & $11(22.0 \%)$ & $8(57.1 \%)$ & 0.011 \\
\hline Planned pregnancy & $89(86.4 \%)$ & $21(56.8 \%)$ & $<0.001$ \\
\hline Gravida* $^{*}$ & $1.82 \pm 0.99$ & $2.18 \pm 1.01$ & 0.082 \\
\hline Parity* & $1.48 \pm 0.65$ & $1.73 \pm 0.67$ & 0.065 \\
\hline Alive child* & $0.44 \pm 0.63$ & $0.70 \pm 0.64$ & 0.050 \\
\hline Abortus* & $0.29 \pm 0.61$ & $0.42 \pm 0.75$ & 0.324 \\
\hline D\&C* & $0.06 \pm 0.24$ & $0.03 \pm 0.17$ & 0.523 \\
\hline Birth weight & $3120.39 \pm 338.10$ & $3109.73 \pm 500.28$ & 0.886 \\
\hline Expecting girl & $65(63.1 \%)$ & $25(67.6 \%)$ & 0.627 \\
\hline Vaginal birth & $58(56.3 \%)$ & $21(56.8 \%)$ & 0.825 \\
\hline
\end{tabular}

${ }^{\star}$ There are some missing values. 
depression and anxiety. Our study confirmed the prevalence of anxiety and mood disorders during pregnancy. Of the obstetric outcomes assessed, low birth weight was the trait most significantly related to depression, and unplanned pregnancy and low income were correlated with the diagnosis of an anxiety disorder.

There are conflicting results in the literature about the prevalence of anxiety during pregnancy. In population-based studies with large sample sizes, the prevalence of anxiety symptoms in the early stages of pregnancy was $15.6 \%$ [17] and $14.2 \%$ [12]. George's et al. study [18] found that anxiety disorders were diagnosed antenatally in $18.8 \%$ of pregnant women in their third trimester. In our study, this number was $20.3 \%$. Our number may be higher than George's et al. [18] because our study was conducted in a tertiary center. When compared with the two aforementioned studies, our study and George's et al. study had higher prevalence of anxiety. The differences in results might also be because anxiety may increase as pregnancy advances. While George's et al. [18] study included women in late gestational stages, we included patients from all trimesters. The aforementioned former studies included patients in the early stages of pregnancy. Participants being in different stages of pregnancy might have contributed to these conflicting results.

In recent studies, depression prevalence among pregnant women was found to be $22 \%$ [19] $21 \%$ [20], and $19.1 \%$ [12]. In a Turkish study, researchers determined the prevalence of depression among women in their first gestational trimester to be $16.8 \%$ [21]. In our study, a depression diagnosis was given to $19.2 \%$ of participants. Depression prevalence in our current study is compatible with the literature.

Like Bödecs et al. [12], we found a relationship between anxiety disorders and low income levels; however, we were unable to show a relationship between depression and income level. This may stem from methodological differences between our study and other studies in the literature. We evaluated participants with SCID-1 instead of using only a scale, so that we could achieve a more definitive diagnosis.

We found that unplanned pregnancies were correlated with the presence of anxiety disorders, as did Morylowska-Topolska et al. [22]. This anxiety may originate from worries about being unprepared for pregnancy; or, conversely, a woman's anxious nature may make her more likely to experience an unplanned pregnancy. The study by Takahashi et al. [23] showed that anxiety disorders were risk factors for unplanned pregnancies.

A recent study conducted by Gawlik et al. [24] showed no significant relationship between de- pressive or anxiety symptoms and obstetric outcomes. Other studies, including this one, have shown a relationship between low birth weight and maternal antenatal depressive symptoms $[11,25]$. Because APGAR is a subjective finding and can be affected by many acute intrapartum problems, we did not test for a relationship between APGAR scores and depression and anxiety disorders.

One major strength of our study is the fact that we used in-person psychiatric evaluations using SCID-1 to diagnose depression and anxiety disorders. The vast majority of other studies have used only questionnaires. However, although our study used a relatively large sample size, one limitation is the missing data and heterogeneity of the timing of the conversation with the participants. Furthermore, since our study was conducted in a university hospital, our data may not be representative of the whole population.

In conclusion, depressive symptoms and anxiety disorders are relatively common in pregnant women, and depressive symptoms might interfere with pregnancy outcomes. Future studies should investigate whether treating depression improves obstetric outcomes. By decreasing unplanned pregnancies by raising awareness of effective birth control methods, the prevalence of anxiety among pregnant women may be reduced.

\section{Conflict of interest}

The authors declare no conflict of interest.

\section{References}

1. Faisal-Cury A, Rossi Menezes P. Prevalence of anxiety and depression during pregnancy in a private setting sample. Arch Womens Ment Health 2007; 10: 25-32.

2. Orr ST, James SA, Reiter JP. Unintended pregnancy and prenatal behaviour among urban black women in Baltimore Maryland: The Baltimore Preterm Birth Study. Ann Epidemiol 2008; 18: 545-51.

3. O'Hara MV, Wisner KL. Perinatal mental illness: definition, description and aetiology. Best Pract Res Clin Obstet Gynaecol 2014; 28: 3-12.

4. Şentürk V. Prevalent psychiatric problems during pregnancy and postpartum period [English]. Kriz Dergisi 2008; 16: 25-34.

5. Llewellyn AM, Stowe ZN, Nemeroff CB. Depression during pregnancy and the puerperium. J Clin Psychiatry 1997; 58: 26-32.

6. Csatordai S, Kozinszky Z, Devosa I, E, Krajcsi A, Sefcsik T, Pál A. Obstetric and sociodemographic risk of vulnerability to postnatal Toth depression. Patient Educ Couns 2007; 67: 84-92.

7. Giardinelli L, Innocenti A, Benni L, et al. Depression and anxiety in perinatal period: prevalence and risk factors in an Italian sample. Arch Womens Ment Health 2012; 15: 21-30.

8. Andersson L, Sundström-Poromaa I, Bixo $M$, Wulff $M$, Bondestam K, åStröm M. Point prevalence of psychiat- 
ric disorders during the second trimester of pregnancy: a population-based study. Am J Obstet Gynecol 2003; 189: 148-54.

9. Borri C, Mauri M, Oppo A, et al. Axis I psychopathology and functional impairment at the third month of pregnancy: results from the Perinatal Depression-Research and Screening Unit (PND-ReScU) Study. J Clin Psychiatry 2008; 69: 1617-24.

10. Grant KA, McMahon C, Austin MP. Maternal anxiety during the transition to parenthood: a prospective study. J Affect Disord 2008; 108: 101-11.

11. Marcus SM. Depression during pregnancy: rates, risks and consequences. Can J Clin Pharmacol 2009; 16: 15-22.

12. Bödecs T, Szilágyi E, Cholnoky P, et al. Prevalence and psychosocial background of anxiety and depression emerging during the first trimester of pregnancy: data from a Hungarian population-based sample. Psychiatr Danub 2013; 25: 352-8.

13. Andersson L, Sundström-Poromaa I, Wulff $M$, Aström $M$, Bixo M. Implications of antenatal depression and anxiety for obstetric outcome. Obstet Gynecol 2004; 104: 467-76.

14. Berle JO, Mykletun A, Daltveit AK, Rasmussen S, Holsten F, Dahl AA. Neonatal outcomes in off-springs of women with anxiety and depression during pregnancy. Arch Womens Ment Health 2005; 8: 181-9.

15. Spielberger CD, Gorsuch RL, Lushene RE. Manual for the State-Trait Anxiety Inventory. Consulting Psychologists Press, Palo Alto, CA, USA 1970.

16. Öner N, LeCompte A. Durumluluk-Sürekli Kaygı Envanteri El Kitabı (State and Trait Anxiety Inventory Handbook). Bogaziçi University Published, Istanbul, Turkey 1983.

17. Rubertsson C, Hellström J, Cross M, Sydsjö G. Anxiety in early pregnancy: prevalence and contributing factors. Arch Womens Ment Health 2014; 17: 221-8.

18. George A, Luz RF, De Tychey C, Thilly N, Spitz E. Anxiety symptoms and coping strategies in the perinatal period. BMC Pregnancy Childbirth 2013; 13: 233.

19. Chang HY, Keyes KM, Lee KS, et al. Prenatal maternal depression is associated with low birth weight through shorter gestational age in term infants in Korea. Early Hum Dev 2014; 90: 15-20.

20. Dmitrovic BK, Dugalić MG, Balkoski GN, Dmitrovic A, Soldatovic I. Frequency of perinatal depression in Serbia and associated risk factors. Int I Soc Psychiatry 2014; 60: 528-32.

21. Akçalı Aslan P, Aydın N, Yazııı E, Aksoy AN, Kirkan TS, Daloglu GA. Prevalence of depressive disorders and related factors in women in the first trimester of their pregnancies in Erzurum, Turkey. Int I Soc Psychiatry 2014; 60: 809-17.

22. Morylowska-Topolska J, Makara-Studzińska M, Kotarski J. The influence of sociodemografic and medical variables on severity of anxiety and depressive symptoms during particular trimesters of pregnancy. Psychiatr Pol 2014; 48: 173-86.

23. Takahashi S, Tsuchiya KJ, Matsumoto K, Suzuki K, Mori N, Takei N. Psychosocial determinants of mistimed and unwanted pregnancy: the Hamamatsu Birth Cohort (HBC) study. Matern Child Health J 2012; 16: 947-55.

24. Gawlik S, Waldeier L, Müller M, Szabo A, Sohn C, Reck C. Subclinical depressive symptoms during pregnancy and birth outcome: a pilot study in a healthy German sample. Arch Womens Ment Health 2013; 16: 93-100.

25. Wado YD, Afework MF, Hindin MJ. Effects of maternal pregnancy intention, depressive symptoms and social support on risk of low birth weight: a prospective study from southwestern Ethiopia. PLoS One 2014; 21: e96304. 